\title{
EDUHEM 2018
}

VIII International conference on intercultural education and International conference on transcultural health: THE VALUE OF EDUCATION AND HEALTH FOR A GLOBAL, TRANSCULTURAL WORLD

\section{PILOT STUDY INTO THE EXECUTIVE FUNCTIONS OF CHILDREN AGED 8-9 BAPNE METHOD}

Ricardo Torró-Biosca (a), Francisco Aparici-Mínguez (a), Antonio Francisco Arnau-Mollá (a)*, Richard Mauricio Ulate-Orozco (a), Dailyn Adriana Cabrera-Quirós (a), Francisco Javier Romero-Naranjo (a)

*Corresponding author

(a) Universidad de Alicante, Department of Innovation and Didactic Training, San Vicente del Raspeig s/n, 03080

Alicante, Spain.*Email: info@antonioarnau.com, bodypercussion@gmail.com

\begin{abstract}
This study aims to generate interest in matters regarding executive functions in children in primary education, and to increase our understanding as to whether the development of these functions in pupils in their third year of primary school can be improved using rhythm and body percussion through the BAPNE method. The study was based on a research protocol with a total of $n=51$ subjects, divided between an experimental group and a control group in the province of Valencia (Spain). The two groups were similar in nature and were of average sociocultural and economic levels. The methodology used was experimental and used measurements and collection of pre- and post-test sample measurements, before and after the BAPNE method was used with the experimental group. Subsequently, statistical analysis was carried out which was factorial in design and analysed the measurements taken before and after the intervention. The results obtained show that BAPNE sessions has a significant positive effects on the executive functions.
\end{abstract}

C 2019 Published by Future Academy www.FutureAcademy.org.UK

Keywords: BAPNE method, body percussion, executive functions, neuromotricity, verbal fluency, working memory. 


\section{Introduction}

The body and its use as a basic, essential, musical instrument linked to the entire complex intellectual system typical of human beings is doubtlessly a never-ending field of study.

In recent years, movement linked to the body has been an area of interest. We are constantly discovering more about the positive effects of movement on the different areas of behaviour. It is important also not to forget that the 21 st century brings with it a range of technological advances -such as smartphones, tablets and social networks- which allow us to constantly feedback data of interest from observations when on field placements. In this sense, on one side technology also allows us to bring in data from science and we can bring the two together through research and implementation in the field of education. On the other hand, education is currently going through a challenging time. Thus, one of the present challenges is thinking more fully about innovative and effective strategies which will allow education to distinguish between knowledge and understanding. The easy access to information and the overstimulation experienced by each and every individual brings with it steadily decreasing levels of attention and low concentration levels.

Previous studies in the literature point out that, setting goals, planning, and putting behaviour creatively and effectively into practice are all skills given to us by our Executive Functions (EF) (Mejía Rodríguez, 2017). For Sholberg, Mateer, \& Stuss (1993) and Tirapu-Ustárroz, Muñoz-Céspedes, \& Pelegrín-Valero (2002), the EF - in addition to planning - include anticipation, choice of goals, choice of actions, self-regulation, self-control and feedback. Mejía Rodríguez (2017) points out that the concept of EF evolved slowly and is related to a variety of cognitive, emotional and behavioural aspects.

In this context, current fields such as dance, sport and music, in which movement is considered an integral part of learning, show us its importance in the mental, physical and intellectual development of humans. Many different authors show how cognitive stimulation can be brought about by movement in various aspects, from motor movement and physical education, to musical tasks involving movement. In the same way, various studies show that exercise encourages quick processing, decision-making and processes involved in attention. These studies all highlight the positive contribution of movement (Matus \& Urrutia, 2017).

According to Trives et al. (2014), Jaques-Dalcroze established our basic understanding as to the relation between attention, movement and body percussion. Following his work, different authors such as Zoltan Kodaly, Carl Orff, Edgar Willems, Maurice Martenot and Javier Romero have deepened our understanding and related it to other aspects through their various methods which use different aspects, such as psychomotoricity in therapy. As part of this development in our understanding, the BAPNE method is one that shows that the EF can be stimulated through its use in these fields. Specifically, BAPNE is a method of cognitive, socio-emotional, psychomotor and neurological rehabilitation stimulation, and is based on neuromotricity. This method makes use of body percussion, music and movement to develop executive intelligence.

Following a search for academic information on scientific databases such as JSTOR, Eric, Dialnet and Scopus, we found that there is evidence of little research into the improvement in executive functions through body percussion, except through the BAPNE Method (Romero-Naranjo, 2013). 
For this reason, the main goal of this paper is to measure the degree of development of executive functions, and consequently to analyse the effect of the BAPNE sessions in each individual school groups. To do this, the study was based on a research protocol with a total of $n=51$ subjects, divided between an experimental and a control groups with similar sociocultural and economic levels in the province of Valencia (Spain).

The results obtained show that BAPNE sessions has a significant positive effects on the executive functions. In particular, the different test carried out show that after the use of the BAPNE method, the experimental group improves in: phonological fluency (which assesses verbal fluency) with a lower number of wrong answers and in the rings test in the length of time used. Therefore, BAPNE can be seen to be an appropriate methodological approach to improve executive functions and an effective tool in the primary school classroom.

After this introduction, the structure of the paper is as follows. The second section briefly reviews the literature on executive functions and movement. The third and fourth sections specifies the research questions and the two main purposes of this paper, respectively. The fifth section defines the research methods. The sixth section presents the main findings, and finally, the last section presents the conclusions.

\section{Problem Statement}

Though body percussion is far from new, the research conducted into the BAPNE Method provides the design of specific activities to bring about cognitive stimulation through body percussion in order to improve the specific aspects of attention and EF in children. Searches were made for academic information on scientific databases such as JSTOR, Eric, Dialnet, Scopus and JCR publications. There is evidence of little research into the improvement in executive functions through body percussion, except through the BAPNE Method (Romero-Naranjo, 2013). Additionally, we had no success in finding research into which executive functions were improved through dance.

\subsection{Executive functions}

Luria (1973) observed that patients with frontal lesions lacked initiative, motivation, self-control of their behaviour and planning of their actions acción (Tirapu-Ustárroz et al., 2002; Tirapu-Ustárroz, MuñozCéspedes, Pelegrín-Valero \& Albéniz-Ferreras, 2005).

The executive functions (EF) according to Lezak (1982) and Mejía Rodríguez (2017) are the abilities which allow us to set goals, carry out planning, and creatively and effectively implement behaviours.

For Sholberg, Mateer, \& Stuss (1993) and Tirapu-Ustárroz, Muñoz-Céspedes, \& Pelegrín-Valero (2002), the EF - in addition to planning - include anticipation, choice of goals, choice of actions, selfregulation, self-control and feedback.

Mejía Rodríguez (2017) points out that the concept of EF evolved slowly and is related to a variety of cognitive, emotional and behavioural aspects. Similarly, Gioia \& Isquith (2004), Baggetta \& Alexander (2016) and Mejía Rodríguez (2017) point out that there are multiple processes that make up the term, such as working memory, cognitive flexibility, initiative, inhibition, monitoring actions, control of regulation of thought and action (Mejía Rodríguez, 2017). 
In this context, Lezak, Howieson, Loring, \& Fischer (2004), Gilbert \& Burgess (2008) and Verdejo \& Bechara (2010) define the EF as "a set of skills involved in the generation, supervision, regulation, execution, and readjustment of behaviour to achieve complex goals, especially those that require a novel and creative approach" (p.227).

Other authors, such as Baggetta \& Alexander, (2016), Tirapu-Ustárroz, Cordero-Andrés, LunaLario, \& Hernáez-Goni (2017) and Mejía Rodríguez (2017), point out that the terms most used in studies to refer to the cognitive processes involved are working memory, flexibility, and inhibition.

\subsection{Movement}

Piek et al. (2004), when exploring the relationship that exists between motor coordination, attention and the executive functions, showed empirical evidence that the deficiencies in the coordination of development can be explained by deficits in the executive functions. The same author showed that various studies (Kaplan, Wilson, Dewey, \& Crawford, 1998; Piek, Pitcher, \& Hay, 1999; Pitcher, Piek, \& Hay, 2003) conclude that there is a significant relationship between the motor and attentional problems in children.

According to Basso \& Suzuki (2017), the EF are strengthened by intense exercise, with effects which last for up to two hours after stopping exercise.

Similarly, different areas of the brain in both hemispheres can be seen to be positively affected whilst singing and performing repetitive motor movements, as this stimulates superior cognitive functions such as attention and planning (Jauset-Berrocal, Tripovik, \& Romero-Naranjo, 2014).

Matus \& Urrutia (2017) showed in a study with children aged between 5 and 6 that there was solid evidence of the effect that exercise has on different cognitive abilities and biological determinants, showing "the need to assess the link between physical aptitude and cognitive skills" (p.10).

Diamond (2012), cited in Mejía Rodríguez (2017), points out that the fact that children are not sitting down for long periods of a time, the fostering of a sense of teamwork, coming together as equals, selfconfidence and happiness all contribute to improved executive functioning and academic achievement.

\section{Research Questions}

3.1. What levels of attention and EF are shown by pupils before implementing the BAPNE Method programme?

3.2. During which activities are EF developed during the implementation of the BAPNE method?

3.3. What difference is there between students who participated in the BAPNE teaching programme and those that did not?

3.4. Is there a possible improvement in $E F$ in students who have carried out a teaching programme using the BAPNE method? What degree of improvement is seen?

\section{Purpose of the Study}

Our aims in this investigation are: 
- To measure the degree of development of executive functions in each individual in the school groups, and to observe the difference between those who have participated in the BAPNE sessions and those who have not, thus determining if the method can bring about an improvement in the development of these functions.

- To improve the tools of each individual participating in the programme to carry out tasks in the classroom.

\section{Research Methods}

The study was carried out with a group of $n=51$ children in their third year of primary school, aged between 8 and 9 . The average age was 8.31 years. The control group consisted of 19 students in a school run in a private-public partnership located in the city of Canals. The entire form group consisted of 23 students, of whom 4 did not participate in the study. On the other hand, the experimental group consisted of 32 students in a religious school located in the city of Ontinyent. In this case, all the students in the form group participated in the study. The socioeconomic and cultural characteristics of the families of both groups were similar, and were found to be average. The distance between the two towns is 26 kilometres. Given this, and the fact they are found in different municipalities, there was no risk of contamination between the two groups.

The first steps in this investigation were to deliver an explanatory dossier about how the study was to be carried out. This was presented to the teaching teams in each establishment. After receiving the goahead from the leadership teams, a meeting was held with the parents where the process was explained. At the end of the meeting, the consent forms were distributed so that parents could sign them and thus give their consent for their children's participation in the study.

The tools used to assess the level of maturity and cognitive achievement in activities related to executive functions in both groups were: the neuropsychological assessment of executive functions in children, ENFEN, and the CSAT-R test of sustained attention.

The methodology used was quasi-experimental in design with measurements and samples before and after the use of the method (pre- and post-tests). Subsequently, statistical analysis which was factorial in design was carried out by Ruth Gasparini Berenguer, a neuropsychologist at Alicante General Hospital. This analysis considered the samples taken before and after the application of the programme.

The programme used with the experimental group lasted 16 weeks between January and May 2017. The students took part in two weekly sessions which each lasted 50 minutes and which took place on Tuesdays and Thursdays. These sessions replaced one music lesson and one physical education (PE) lesson one week. Due to this replacement, the experimental group did not welcome the method, as PE was one of their favourite subjects. Despite this, and despite the difficulties of working with such a group, there was a notable change seen in their attitude towards the Method during the course of the 16 weeks.

The intervention was carried out using a programme of neuromotricity using the BAPNE Method. This was done using a protocol of activities which are explained in publications by Dr. Francisco Javier Romero-Naranjo and entitled 'Body Percussion - Teaching Manual - Volume 1'. The Method is a programme for a whole academic year which contains musical motor activities in order to develop attention, cognition and EF in healthy children i.e. with generally normal levels of development. According to the 
author himself, the aim is not to perform choreographed routines, but for children to maintain a high level of attention and concentration (Romero Naranjo, 2017, p.14).

Unlike the experimental group, the control group did not undertake the neuromotricity programme using the BAPNE Method and followed their normal routines without undergoing any change to the development of their academic programme.

After the 16 weeks of the programme had passed, the same sets of assessments using CSAT-R (Servera \& Llabrés, 2015) and ENFEN (Portellano, Martínez, \& Zumárraga, 2009) were conducted with both groups, and the results from this study are based on this analysis. These results have been compared by the BAPNE research group with other studies carried out using the method in order to be able to come to more significant conclusions.

\section{Findings}

The analysis of the data was carried out using the t-Student test to compare the mean averages of separate samples. A level of statistical significance of 0.05 was used. The statistical software used was IBM SPSS v24 for Mac. The graphs and tables have been made using Microsoft Excel for Mac for greater aesthetic appeal.

\subsection{F1: phonological fluency}

In the first phase of the pre-test, there are statistically significant differences between the experimental and the control group $(\mathrm{p}=0.007)$ and the difference between the average of the groups is 0.52 . After conducting the post-test, no statistically significant evidence was obtained, but when looking at the difference between the post- and the pre-test and comparing these mean averages, we see significant differences between the two groups $(\mathrm{p}=0.027)$.

Table 01. Test of independent samples: Levene's test of equality of variances and t-test on equality of averages

\begin{tabular}{|c|c|c|c|c|c|c|c|}
\hline \multicolumn{4}{|c|}{ Levene's test of equality of variances } & \multicolumn{4}{|c|}{ t-test on equality of averages } \\
\hline & & $\mathrm{F}$ & Sig. & $\mathrm{t}$ & $\mathrm{gl}$ & Sig. & $\begin{array}{l}\text { Difference between } \\
\text { mean averages }\end{array}$ \\
\hline \multirow[t]{2}{*}{$\begin{array}{l}\text { PRE } \\
\text { F1-I }\end{array}$} & $\begin{array}{l}\text { Assumes equality of } \\
\text { variances }\end{array}$ & 22.604 & 0 & 2.321 & 49 & 0.024 & 0.52 \\
\hline & $\begin{array}{l}\text { Does not assume } \\
\text { equality of variances }\end{array}$ & & & 2.863 & 41.274 & 0.007 & 0.52 \\
\hline \multirow[t]{2}{*}{$\begin{array}{l}\text { POST } \\
\text { F1-I }\end{array}$} & $\begin{array}{l}\text { Assumes equality of } \\
\text { variances }\end{array}$ & 0.574 & 0.452 & 0.293 & 49 & 0.771 & 0.049 \\
\hline & $\begin{array}{l}\text { Does not assume } \\
\text { equality of variances }\end{array}$ & & & 0.32 & 47.482 & 0.75 & 0.049 \\
\hline \multirow[t]{2}{*}{ F1-I } & $\begin{array}{l}\text { Assumes equality of } \\
\text { variances }\end{array}$ & 5.35 & 0.025 & -1.967 & 49 & 0.055 & -0.47 \\
\hline & $\begin{array}{l}\text { Does not assume } \\
\text { equality of variances }\end{array}$ & & & -2.286 & 48.375 & $\mathbf{0 . 0 2 7}$ & -0.47 \\
\hline
\end{tabular}

Note: The table shows the results of the Levene's test of equality of variances and t-test on equality of averages. Specifically, the first two rows, PRE F1-I and POST F1-I, refer to the results of the 
phonological fluency intrusions in the pre- and post-test, respectively. Lastly, the third row, F1-I, refers to the differences between the phonological fluency intrusions in the pre- and post-test.

Table 02. Group statistics

\begin{tabular}{|l|l|l|l|l|}
\hline & Group & $\mathbf{N}$ & Average & $\begin{array}{l}\text { Standard } \\
\text { deviation }\end{array}$ \\
\hline \multirow{3}{*}{ PRE F1-I } & Experimental & 32 & 0.63 & 0.942 \\
\cline { 2 - 5 } & Control & 19 & 0.11 & 0.315 \\
\hline \multirow{3}{*}{ POST F1-I } & Experimental & 32 & 0.31 & 0.644 \\
\cline { 2 - 6 } & Control & 19 & 0.26 & 0.452 \\
\hline \multirow{2}{*}{ F1-I } & Experimental & 32 & -0.31 & 0.965 \\
\cline { 2 - 6 } & Control & 19 & 0.16 & 0.501 \\
\hline
\end{tabular}

Note: The table shows the number of students $(\mathrm{N})$, the mean and the standard deviation of the phonological fluency intrusions in the pre- (PRE F1-I) and post-test (POST F1-I), respectively. In each case, the results are disaggregated for the experimental and control groups.

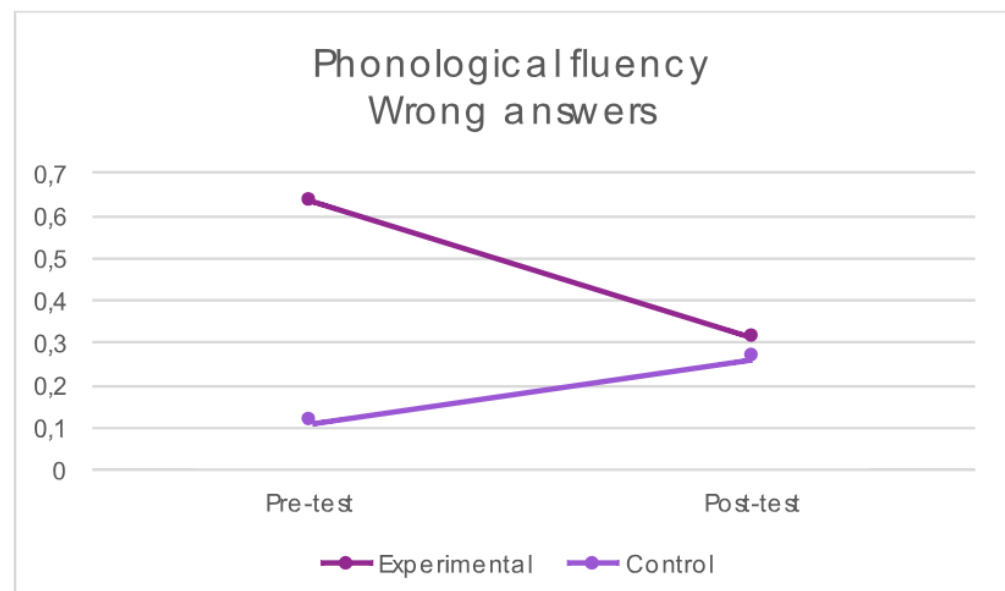

Figure 01. Phonological fluency: Wrong answers. This figure shows the mean values of the wrong answers conducted by the experimental and control groups in the phonological fluency intrusions for the pre- and post-test.

\subsection{A: Rings}

Statistically significant differences have been found between the average of the experimental group and the control group when considering the difference between the post-test minus the pre-test $(\mathrm{p}=0.04)$. We also see statistically significant differences in the pre-test $(\mathrm{p}=0.002)$ for the total time spent on the rings activity; this was 55.054. When conducting the post-test, such differences were not found.

Table 03. Test of independent samples: Levene's test of equality of variances and t-test on equality of averages

\begin{tabular}{|l|l|l|l|l|l|l|}
\hline \multicolumn{2}{|l|}{ Levene's test of equality of variances } & \multicolumn{3}{|l|}{ t-test on equality of averages } \\
\hline & F & Sig. & $\mathrm{t}$ & $\mathrm{gl}$ & $\begin{array}{l}\text { Sig. } \\
\text { (bilateral) }\end{array}$ & $\begin{array}{l}\text { Difference } \\
\text { between } \\
\text { mean } \\
\text { averages }\end{array}$ \\
\hline
\end{tabular}


Selection and peer-review under responsibility of the Organizing Committee of the conference

\begin{tabular}{|l|l|l|l|l|l|l|l|}
\hline \multirow{2}{*}{$\begin{array}{l}\text { PRE } \\
\text { A-T }\end{array}$} & $\begin{array}{l}\text { Assumes equality of } \\
\text { variances }\end{array}$ & 5.385 & 0.025 & 2.643 & 49 & 0.011 & 55.05 \\
\cline { 2 - 8 } & $\begin{array}{l}\text { Does not assume } \\
\text { equality of variances }\end{array}$ & & & 3.216 & 43.47 & $\mathbf{0 . 0 0 2}$ & $\mathbf{5 5 . 0 5}$ \\
\hline \multirow{2}{*}{$\begin{array}{l}\text { POST } \\
\text { A-T }\end{array}$} & $\begin{array}{l}\text { Assumes equality of } \\
\text { variances }\end{array}$ & 7.355 & 0.009 & 1.605 & 49 & 0.115 & 22.91 \\
\cline { 2 - 8 } \\
$\begin{array}{l}\text { Does not assume } \\
\text { equality of variances }\end{array}$ & & & 1.955 & 43.302 & 0.057 & 22.91 \\
\hline A-T & $\begin{array}{l}\text { Assumes equality of } \\
\text { variances }\end{array}$ & 4.849 & 0.032 & -1.72 & 49 & 0.092 & -32.13 \\
\cline { 2 - 8 } & $\begin{array}{l}\text { Does not assume } \\
\text { equality of variances }\end{array}$ & & & -2.122 & 41.289 & $\mathbf{0 . 0 4}$ & $\mathbf{- 3 2 . 1 3}$ \\
\hline
\end{tabular}

Note: The table shows the results of the Levene's test of equality of variances and t-test on equality of averages. Specifically, the first two rows, PRE A-T and POST A-T, refer to the results of the Rings activity pre- and post-test, respectively. Lastly, the third row, F1-I, refers to the differences between the Rings activity in the pre- and post-test.

Table 04. Group statistics

\begin{tabular}{|l|l|l|l|l|}
\hline & Group & N & Average & $\begin{array}{l}\text { Standard } \\
\text { deviation }\end{array}$ \\
\hline \multirow{3}{*}{ PRE A-T } & Experimental & 32 & 277.84 & 86.851 \\
\cline { 2 - 5 } & Control & 19 & 222.79 & 32.981 \\
\hline \multirow{2}{*}{ POST A-T } & Experimental & 32 & 211.97 & 59.583 \\
\cline { 2 - 5 } & Control & 19 & 189.05 & 22.414 \\
\hline \multirow{2}{*}{ A-T } & Experimental & 32 & -65.88 & 78.571 \\
\cline { 2 - 5 } & Control & 19 & -33.74 & 26.327 \\
\hline
\end{tabular}

Note: The table shows the number of students $(\mathrm{N})$, the mean and the standard deviation of the Rings activity pre- (PRE A-T) and post-test (POST A-T), respectively. In each case, the results are disaggregated for the experimental and control groups.

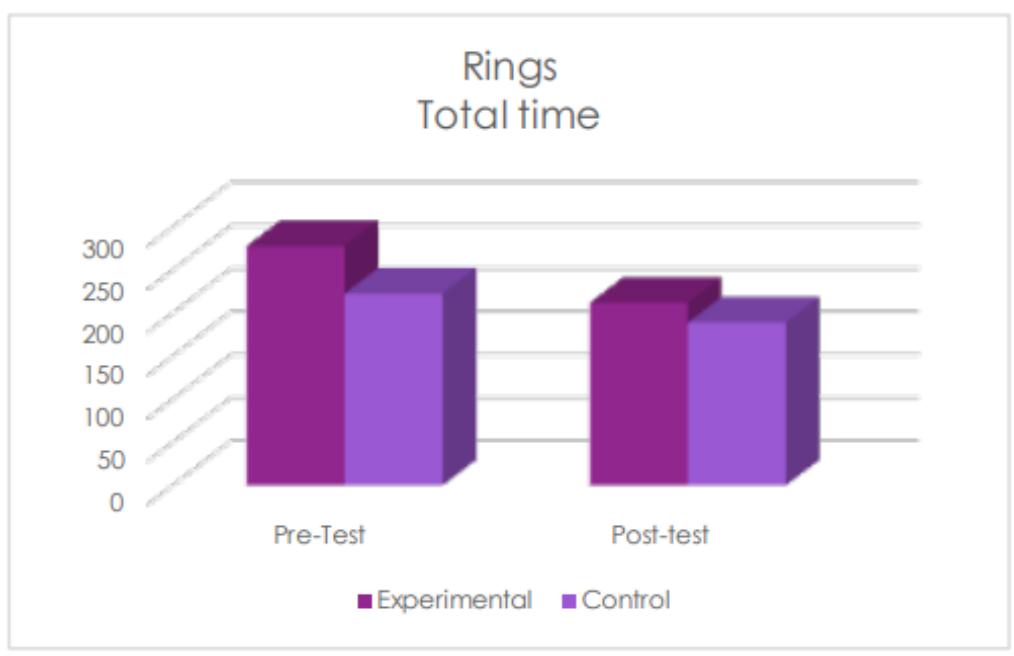

Figure 02. Rings: Total time spent. Note: This figure shows the mean values of the total time spent by the experimental and control groups in the Rings activity for the pre- and post-test. 


\section{Conclusion}

Following this study, it can be shown by looking at the quantitative analysis of the pre- and posttests that the final results shown in the ENFEN test show positive results on the phonological fluency and rings tests. The results obtained lead us to think that the BAPNE Method could be a highly effective tool in the primary school classroom. Following the quantitative study carried out during the course of 16 weeks, we can state that the experimental group showed improvement in:

Phonological fluency (which assesses verbal fluency), as the experimental group improved, with a lower number of wrong answers (see figure 1).

The rings test, which measures abstract reasoning, working memory, and planning, as the experimental group improved significantly and particularly in the length of time used (see figure 2).

Therefore, BAPNE can be seen to be an appropriate methodological approach on which to use other tests related to executive functions. This would thus increase the number of subjects and allow a longitudinal study to be undertaken. This would allow the BAPNE research group to move forward in its main aim, which is to show the validity of the method using quantitive studies.

\section{Acknowledgments}

We would like to thank the teachers at Colegio Santa María de Ontinyent and at Colegio Cervantes de Canals for their participation and enthusiasm when carrying out this investigation.

\section{References}

Baggetta, P., \& Alexander, P. A. (2016). Conceptualization and operationalization of executive function. Mind, Brain, and Education, 10(1), 10-33.

Basso, J. C., \& Suzuki, W. A. (2017). The effects of acute exercise on mood, cognition, neurophysiology, and neurochemical pathways: a review. Brain Plasticity, 2(2), 127-152. doi: 10.3233/BPL-160040

Diamond, A. (2012). Activities and programs that improve children's executive functions. Current directions in psychological science, 21(5), 335-341.

Gilbert, S. J., \& Burgess, P. W. (2008). Executive function. Current Biology, 18(3), R110-R114.

Gioia, G. A., \& Isquith, P. K. (2004). Ecological Assessment of Executive Function in Traumatic Brain Injury. Developmental Neuropsychology, 25(1-2), 135-158.

Jauset-Berrocal, J. A., Tripovik, Y., \& Romero-Naranjo, F. J., (2014). El método BAPNE y su repercusión en las capacidades cognitivas. XII Jornadas de Redes de Investigación en Docencia Universitaria. Universidad de Alicante.

Kaplan, B. J., Wilson, B. N., Dewey, D., \& Crawford, S. G. (1998). DCD may not be a discrete disorder. Human movement science, 17(4-5), 471-490.

Lezak, M. D. (1982). The problem of assessing executive functions. International journal of Psychology, 17(1-4), 281-297.

Lezak, M. D., Howieson, D. B., Loring, D. W., \& Fischer, J. S. (2004). Neuropsychological assessment. Oxford University Press, USA.

Matus, R. I., \& Urrutia, J. A. (2017). Aptitud física y habilidades cognitivas. Revista Andaluza de Medicina del Deporte, 10(1), 9-13. doi: 10.1016/j.ramd.2016.04.004

Mejía Rodríguez, G. L. (2017). Funciones ejecutivas en niños y niñas de primaria: la importància de las Inteligencias Múltiples como metodología de enseñanza-aprendizaje. (Tesis doctoral). Universidad Autónoma de Barcelona, Berratella, Barcelona. 
Piek, J. P., Dyck, M. J., Nieman, A., Anderson, M., Hay, D., Smith, L. M., \& Hallmayer, J. (2004). The relationship between motor coordination, executive functioning and attention in school aged children. Archives of clinical Neuropsychology, 19(8), 1063-1076.

Piek, J. P., Pitcher, T. M., \& Hay, D. A. (1999). Motor coordination and kinaesthesis in boys with attention deficit-hyperactivity disorder. Developmental Medicine and Child Neurology, 41(3), 159-165.

Pitcher, T. M., Piek, J. P., \& Hay, D. A. (2003). Fine and gross motor ability in males with ADHD. Developmental medicine and child neurology, 45(8), 525-535.

Portellano, J. A., Martínez, R., \& Zumárraga, L. (2009). ENFEN Evaluación Neuropsicológica de las Funciones Ejecutivas en Niños. Madrid: Tea Ediciones.

Romero Naranjo, F. J. (2013). Science \& art of body percussion: a review. Journal of human sport and exercise, 8(2), 442-457. Retrieved from: http://hdl.handle.net/10045/29740

Romero Naranjo, F. J. (2017). Bodypercussion - Programación Didáctica Vol. 1, Alicante, España: Ramón Torres Gosálvez

Servera, M., \& Llabrés, J. (2015). CSAT-R. Tarea de Atención Sostenida en la Infancia-Revisada. Madrid: Tea Ediciones.

Sholberg, M. M., Mateer, C. A., \& Stuss, D. T. (1993). Contemporary approaches to the management of executive control dysfunction. The Journal of Head Trauma Rehabilitation, 8(1), 45-58.

Tirapu-Ustárroz, J., Muñoz-Céspedes, J. M., \& Pelegrín-Valero, C. (2002). Funciones ejecutivas: necesidad de una integración conceptual. Revista de neurología, 34(7), 673-685.

Tirapu-Ustárroz, J., Muñoz-Céspedes, J. M., Pelegrín-Valero, C., \& Albéniz-Ferreras, A. (2005). Propuesta de un protocolo para la evaluación de las funciones ejecutivas. Revista de neurología, 41(3), 177186.

Tirapu-Ustarroz, J., Cordero-Andres, P., Luna-Lario, P., \& Hernaez-Goni, P. (2017). Proposed model of executive functions based on factorial analyses. Revista de neurologia, 64(2), 75-84.

Trives-Martínez, E. A., Romero-Naranjo, F. J., Pons-Terrés, J. M., Romero-Naranjo, A. A., CrespoColomino, N., Liendo-Cárdenas, A., Jauset-Berrocal, J. A., \& Quarello, A. (2014). Los métodos didáctico musicales y la atención en relación al movimiento. XII Jornadas de Redes de Investigación en Docencia Universitaria. Universidad de Alicante.

Verdejo-García, A., \& Bechara, A. (2010). Neuropsicología de las funciones ejecutivas. Psicothema, 22(2), 227-235. 